\title{
First evaluations of oxygen-ozone therapy in antibiotic-resistant infections
}

\author{
Marianno Franzini, ${ }^{1}$ Luigi Valdenassi, ${ }^{1,2}$ Giulia Ionita ${ }^{2}$ \\ ${ }^{1}$ Oxygen-Ozone Therapy Scientific Society, Gorle (BG); ${ }^{2}$ Department of Internal Medicine and \\ Medical Therapy, University of Pavia, Italy
}

\begin{abstract}
Acquired antibiotic resistance represents one of the main restrictions to an effective antibacterial chemotherapy.

The continuous growth of the phenomenon draws a therapeutical problem to eradicate infections. Ozone presents known properties, such as antibacterial, antiviral, anti-fungal, anti-inflammatory, analgesic, immunomodulation, and reactivation of microcirculation.

Oxygen-ozone therapy has no collateral effects, it is minimally invasive, it is not painful and it does not cause allergic or toxic reactions or drug-drug interactions. Therefore, oxygen-ozone therapy has proved to be useful to control and run out infections in patients with a noted antimicrobial resistant pathology.

We are evaluating the best protocol to treat these pathologies, to obtain the most efficient therapeutical response.
\end{abstract}

\section{Introduction}

Antimicrobial resistance is a microorganism's ability to resist the action of one or more antimicrobial agents. ${ }^{1,2}$

The efficiency of antibiotics is compromised by a growing number of antibiotic-resistant pathogens. Antibiotic resistance, which is implicated in elevated morbidity and mortality rates as well as in the increase of treatment costs, is considered to be one of the major global public health threats. ${ }^{3}$

If a widespread outbreak were to occur, we could expect around 200,000 people to be affected by a bacterial blood infection that could

\author{
Correspondence: Marianno Franzini, Oxygen-Ozone Therapy Scientific \\ Society (SIO0T), via Roma 69, 24020 Gorle (BG), Italy. \\ Tel.: +39.035.300903 - +39.035.2922550. \\ E-mail: marianno.franzini@gmail.com \\ Key words: Antibiotic-resistance; infections; oxygen-ozone therapy. \\ Received for publication: 12 January 2016. \\ Accepted for publication: 24 February 2016. \\ (C) Copyright M. Franzini et al., 2016 \\ Licensee PAGEPress, Italy \\ Ozone Therapy 2016; 1:5838 \\ doi:10.4081/ozone.2016.5838
}

This article is distributed under the terms of the Creative Commons Attribution Noncommercial License (by-nc 4.0) which permits any noncommercial use, distribution, and reproduction in any medium, provided the original author(s) and source are credited. not be treated effectively with existing drugs. ${ }^{4}$ For instance, $5.7 \%$ of all Klebsiella pneumoniae strains isolated in 2014 in European countries were resistant to all groups of antimicrobial agents usually used (fluoroquinolones, third-generation cephalosporins, aminoglycosides and carbapenems); overall, more than $80 \%$ of these isolates were reported from Greece and Italy. ${ }^{2}$

Antibiotic resistance can occur as a result of antibiotics exerting selective pressure leading to expansion of strains with resistance mutations or those that have acquired resistance genes via horizontal gene transfer. ${ }^{5}$ The multidrug efflux systems contribute significantly to the increased resistance to multiple antibiotics in bacteria; we can also find a production of $\beta$-lactamases or aminoglycosidemodifying enzymes and specific resistance mechanisms in different pathogens. ${ }^{3}$

Ozone $\left(\mathrm{O}_{3}\right)$ is a potent oxidant and an important disinfectant, acting on microorganisms by means of oxidation of their biological material. It has been reported that $\mathrm{O}_{3}$ can be employed as a bactericidal agent under various forms, such as ozonated saline solution, ozonated water, ozonated oil, ozone associated with other substances, and more frequently the gaseous $\mathrm{O}_{2} / \mathrm{O}_{3}$ mixture. ${ }^{6}$

Most studies on oxygen-ozone therapy established that ozone, when used in vitro, could destroy all kinds of bacteria, gram positives and gram negatives. More, it has been suggested that microorganisms sensitivity to antibiotics growths when ozone is used, and also bacterial sensitivity to the action of complement of immune system. ${ }^{7}$ In summary, the reason for ozone's capacity to kill viruses and bacteria is based on its very high oxidation potential, which originates in its turn directly from the structure of the ozone molecule. ${ }^{8}$ Cellular membranes are the first target of ozone. Modifications induced by ozone on intracellular contents (oxidation of plasmatic proteins, alteration of cells functions) probably occur for the action of second oxidant molecules, which are produced by lysis of membrane lipids. In fact, by means the production of reactive oxygen species (ROS) $\left(\mathrm{H}_{2} \mathrm{O}_{2},-\mathrm{OH}, \mathrm{O}^{2}\right)$, ozone acts as an oxidant agent like it occurs in leucocytes during phagocytosis. It is plausible to imagine that such an increase is the responsible of ozone bactericidal effect against both aerobe and anaerobe bacteria, considering that the latter ones are poor in enzymes, such as superoxide dismutase, which is able to neutralize oxidant action of those free radicals. In reality, several studies showed that the mechanism on the basis of such a bactericidal effect occurs indirectly by interaction between ROS and enzymatic structures of leucocytes. In particularly, it seems that $\mathrm{H}_{2} \mathrm{O}_{2}$, which is produced after blood ozonization, is the responsible of nuclear factor-kB activation, which is needed for activation of genes transcription of different cytokines (interferon- $\beta$, tumor necrosis factor- $\alpha$, interleukin-2 and -6) in T lymphocytes and in monocytes. ${ }^{9}$

The local deterioration of plasmatic membranes is the direct cause of the destruction of bacteria; bacterial cells lose their capacity to live, to reproduce, or both. The ozone effect against pathogen mycetes modifies first their extern structure (cytoplasmic membrane) and, subsequently, intracellular membranes are compromised. As a result of this 
action, pathogen mycetes hyphas flatten and fold, with the appearance of membranes defects to the complete destruction of all fungal structure components. Antiviral mechanisms are more complex. Ozone molecules action lead to several results: partial destruction of viral envelopes and loss of its properties; inactivation of intracellular reverse transcriptase, with the consequent inhibition of transcription processes and protein synthesis, and, thus, of new viral particle formation; alteration of viral capacity to combined with target cells receptors. Moreover, it has been shown that ozone can destroy both intracellular and extracellular viruses. ${ }^{7}$

\section{Materials and Methods}

All procedures were done at the oxygen-ozone therapy surgery in Bergamo, Italy. Oxygen-ozone therapy has been used and studied there for 33 years.

Ozone is generated by a Medical 95 Computerized Photometric System produced by Multiossigen srl., Gorle (BG), Italy.

Nine patients were selected; they started the oxygen-ozone therapy after a failed healing of an infectious disease, after repeated cycles of broad-spectrum antibiotics. Three of these patients underwent operations of prosthesis replacement: one woman replaced the shoulder joint, one woman had two operations for the left knee prosthesis and the third one came to our surgery after four orthopedics operations for the left knee. We selected also a case of osteomyelitis, a case of prostate infection, a case of recurrent ano-rectal fistula, a case of hepatitis $\mathrm{C}$ virus with clinical history of medium and bigger vessels inflammation. All patients presented skin alterations and cutaneous fistulas amenable to the infectious disease.

In all cases we chose a major ozone autohemotherapy with a concentration between 20 and $40 \mu \mathrm{g}$; the oxygen-ozone mixture was infused in surgery with a number of sessions we chose according to therapy response and to extension of initial lesion/pathology observed before starting therapy. The number of sessions ranged from minimum 3 to maximum 30. Patients were treated also with subcutaneous infiltrations of oxygen-ozone mixture in the skin lesion area, with a concentration of 2-3 $\mu$ g for each microinjections of $5 / 10$ cc. We injected for each limb from 100 to $150 \mathrm{cc}$.

Two patients were treated with rectal insufflation of oxygen-ozone mixture, with a concentration from 20 to $30 \mu \mathrm{g}$ and an amount of 150 cc for each session.

Patients with large skin ulcerous lesions in inferior limbs with pain and conspicuous lack of substance were treated with bag therapy in slightly hyperbaric conditions, with a therapy of 15 min for each limb.

\section{Results}

Notable disinfection, if not a disappearance of involved germs in the infectious disease, are the effects of oxygen-ozone therapy by means major ozone autohemotherapy, in association with subcutaneous injections. Our results showed that the application of ozone prevents the worsening of wounds and it improves the healing of infected tissues.

Moreover, when $\mathrm{O}_{3}$ is applied in autohemotherapy, the infective status of patients improves with an optimal adjustment in C-reactive protein (CRP) and erythrocyte sedimentation rate values.

We can also notice that $2 / 3$ sessions of oxygen-ozone therapy per week can give better results than a treatment with only 1 session per week, because they are able to keep the immunity factors in an elevated level. Moreover, the use of middle concentrations of ozone, such as
30-40 $\mu \mathrm{g}$, is preferable to more elevated or lower concentrations. In this way we can obtain the best therapeutical response by the immunity system. In fact, we can notice that CRP values reduced until we had a two session per week rate; in the moment we chose to reduce the rate to 1 session per week, CRP values enhanced. Our experience suggests that, to a definitive resolution of pathology, 2 sessions of major ozone autohemotherapy per week are necessary during at least one month, since the objective and subjective result consolidation.

We mention here that bactericidal activity of ozone is shown when, in vitro, a dilution of bacterial broth medium of $1 / 1000$ is made; if instead a dilution of bacterial broth medium of $1 / 100$ or $1 / 10$ is made, the effect of ozone activity is only a bacteriostatic one, with a new growth of bacteria after 24-30 h from the inoculum of oxygen-ozone mixture. ${ }^{9}$ So, we can conjecture that an elevated bacterial load needs a more frequent oxygen-ozone therapy to reach the bactericidal effect, with the abolition of bacterial growth.

One patient was affected by chronic lymphatic leukemia; from hematochemical examinations no pathology aggravation were noticed. Therefore, the therapy is not contraindicated in presence of hematopoietic system pathologies. In general, hematological panel of no patient is mutated after major ozone autohemotherapy.

\section{Discussion}

It has been suggested in many studies that ozone can support antibiotic therapy and provide benefits in the treatment of infectious disorders.

For instance, Gulmen et al. reported that simultaneous application of vancomycin and ozone was also noticed to be effective in alleviation of mediastinitis related inflammation. These findings suggested that ozone displays an antimicrobial activity and supports standard antibiotic regimen by enhancing bacterial elimination in experimental mediastinitis methicillin-resistant Staphylococcus aureus. ${ }^{10}$ Daulbaeva et al. reported that ozone therapy of wounds of the face and neck notably increased the sensitivity of microorganisms to antibiotics in $79 \%$ cases. ${ }^{11}$ Belianin et al. reported that four-month addition of dissolved $\mathrm{O}_{3}$ infusions to chemotherapy eliminated the resistance of isolated Mycobacterium tuberculosis to isoniazid and/or rifampicin. ${ }^{12}$

Therefore, according to literature data, we decided to administer oxygen-ozone to patients with chemotherapy resistant infections.

In all cases therapy has been useful to deal with pathologies - no matter the microorganism involved - and the resolution was confirmed by physical examination and laboratory findings.

\section{Conclusions}

Repetition of treatment of refractory infections requires a protract cycle with broad-spectrum antibiotics (at least 4 months). It is also necessary a combination of many antibiotics. ${ }^{1}$

In 2009 the Infectious Disease Society of America took stock of the research for new antibiotics: it discovered only 16 new antimicrobial molecules in development. ${ }^{13}$

Considering that the antibiotic resistance is growing, we believe ozone can constitute a concrete possibility in the future to treat infections not properly responding to chemotherapy.

In summary, we hope oxygen-ozone therapists carry on the research about the treatment of infections to increase the number of data at our disposal. 


\section{References}

1. Fauci AS, Braunwald E, Kasper DL, Hauser SL, Longo DL, Jameson $\mathrm{JL}$, Loscalzo J, eds. Harrison's principles of internal medicine. $17^{\text {th }}$ ed. New York: McGraw-Hill; 2008.

2. European Centre for Disease Prevention and Control. Antimicrobial resistance surveillance in Europe 2014. Annual report of the European Antimicrobial Resistance Surveillance Network (EARS-Net). Stockholm: ECDC; 2015. Available from: http://ecdc.europa.eu/en/publications/Publications/antimicrobialresistance-europe-2014.pdf

3. Lin J, Nishino K, Roberts MC, et al. Mechanisms of antibiotic resistance. Front Microbiol 2015;6:1-3.

4. Cabinet Office. National risk register of civil emergencies - 2015 edition. London: Cabinet Office; 2015. Available from: https://www. gov.uk/government/uploads/system/uploads/attachment_data/file/4 19549/20150331_2015-NRR-WA_Final.pdf

5 Webber MA, Whitehead RN, Mount M, et al. Parallel evolutionary pathways to antibiotic resistance selected by biocide exposure. J Antimicrob Chemother 2015;70:2241-8.
6. Fontes B, Cattani Heimbecker AM, de Souza Brito G, at al. Effect of low-dose gaseous ozone on pathogenic bacteria. BMC Infect Dis 2012;12:358.

7. Schwartz A, Kontorschikova CN, Malesnikov OV, et al. Guia para el uso medico del ozono. Madrid: Aepromo; 2011.

8. Rilling S, Viebahn R. The use of ozone in medicine. 2nd rev ed., 1st Eng ed. Berlin: Haug Publisher; 1987.

9. Luongo C, Lettieri A, Sammartino A, et al. Effetto antimicrobico dell'ozono su colture di Pseudomonas aeruginosa e Staphylococcus aureus. Riv Ital Ossigeno-Ozonoter 2002;1:13-8.

10. Gulmen S, Kurtoglu T, Meteoglu I, et al. Ozone therapy as an adjunct to vancomycin enhances bacterial elimination in methicillin resistant Staphylococcus aureus mediastinitis. J Surg Res 2013;185:64-9.

11. Daulbaeva AA, Ba zakova GT, Effect of ozone on antibiotic sensitivity of microorganisms. Stomatologiia (Mosk.) 2003;82:36-8.

12. Belianin II, Shmelev EI, Changes in drug resistance of Mycobacteria in the simultaneous use of chemotherapy and intravenous infusions of dissolved ozone. Probl Tuberk Bolezn Legk 2004;7:32-5.

13. McKenna M. Il nemico dentro. Le Scienze 2011;514:58-65. 